\title{
Validating a 3E Rubric Assessing Pre-service Science Teachers' Practical Knowledge of Inquiry Teaching
}

\author{
Jianlan Wang ${ }^{1^{*}}$, Stacey Sneed ${ }^{1}$, Yuanhua Wang ${ }^{1}$ \\ ${ }^{1}$ Texas Tech University, USA
}

Received 25 March 2019 - Revised 20 June 2019 - Accepted 23 September 2019

\begin{abstract}
Inquiry teaching in science education has been widely advocated for decades. It is a critical learning objective in many science teacher preparation programs. Despite its importance, it is not effectively implemented in science classrooms. One of the reasons is the lack of reliable and valid instruments that provide practical definition, concrete guideline, and objective assessment for the practice of inquiry teaching. To fill this gap, we designed a $3 \mathrm{E}$ rubric based on the $5 \mathrm{E}$ learning model as one specific form of inquiry teaching to measure preservice teachers' practice at different phases of a science lesson. In this study, we thoroughly introduced the $3 \mathrm{E}$ rubric and its use. Through drawing on 76 elementary pre-service science teachers' teaching videos, we analyzed its reliability and validity with the tools of Intraclass Correlation Coefficient, Fleiss' kappa, and Pearson correlation. According to the results, the $3 \mathrm{E}$ rubric is a reliable and valid tool to assess pre-service teachers' practical knowledge of inquiry teaching. The contributions of this rubric to the teaching and research in science teacher preparation are discussed and future research directions are proposed.
\end{abstract}

Keywords: 3 E rubric, pre-service teachers, inquiry teaching

\section{INTRODUCTION}

Inquiry teaching has been the core in science education reforms for decades (Anderson, 2002; Windschitl, 2003). It is believed to be a promising pedagogical approach to accommodate science practices required by Next Generation Science Standards in the United States (NRC, 2012), such as constructing explanations and engaging in argumentation (Crawford, 2014). There are empirical studies supporting that inquiry teaching could potentially promote student conceptual understanding of and interest towards science (Minner, Levy \& Century, 2010; Palmer, 2009). While inquiry teaching is widely advocated, effective examples are rarely observed in many science classrooms (Capps \& Crawford, 2013). Meltzer and Otero (2015) address that one of the unanswered questions is "despite the widespread and long-standing support for the 'inductive' method of instruction-referred to by various names such as 'inquiry', 'scientific practices', etc. - there has never been any successful, long-lasting, and broad-based implementation of this method either in high school or college physics courses?" (p. 455).

One of the reasons accounting for the ineffective implementation of inquiry teaching is the lack of a precise operational definition (Bybee, 2000). There are several derivatives of inquiry teaching, such as model-based instruction (Windschitl, Thompson, \& Braaten, 2008), problem-based learning (Kolodner et al., 2003) and active learning (Freeman et al., 2013), which share some similarities in nature such as being student-centered and contextrich. However, those similarities have not been indisputably summarized or referred to as the defining features of inquiry teaching. Due to the ambiguity, there is work challenging inquiry teaching that portrays it as teachers acting in a hands-off manner and students carry out learning through self-guided investigations (Kirschner, Sweller \& Clark, 2006), which leads to additional work supporting inquiry teaching while criticizing their opponents for mistakenly defining inquiry teaching (Hmelo-Silver et al., 2007). The loose definition of inquiry teaching has hindered the efforts of exploring its efficacy in comparison to other instructional approaches. For instance, studies examining the effectiveness of inquiry teaching in science classrooms, especially large-scale quantitative studies, rely on students' perception rather than the actual implementation of inquiry teaching (Fook et al, 2016; Zafra-

(C) 2020 by the authors; licensee Modestum Ltd., UK. This article is an open access article distributed under the terms and conditions of the Creative Commons Attribution License (http://creativecommons.org/licenses/by/4.0/).

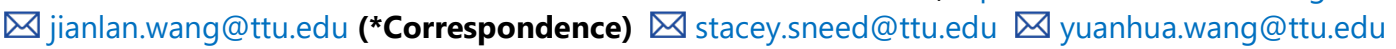




\section{Contribution of this paper to the literature}

- This paper suggests a practical definition of inquiry teaching in the context of science teacher preparation.

- This paper suggests a user-friendly guideline of inquiry teaching for pre-service teachers.

- This paper validates a rubric for the assessment of science pre-service teachers' practice of inquiry teaching through the 5E model.

Table 1. The spectrum of inquiry teaching

\begin{tabular}{|c|c|c|c|}
\hline Types of inquiry & Question & Investigation & Explanation \\
\hline $\begin{array}{l}\text { 1- Confirmation inquiry. Students confirm a principle through an activity } \\
\text { when the results are known in advance }\end{array}$ & $x$ & $x$ & $x$ \\
\hline $\begin{array}{l}\text { 2- Structured inquiry. Students investigate a teacher-presented question } \\
\text { through a prescribed procedure }\end{array}$ & $x$ & $x$ & \\
\hline $\begin{array}{l}\text { 3- Guided inquiry. Students investigate a teacher-presented question using } \\
\text { student-designed/selected procedures }\end{array}$ & $x$ & & \\
\hline $\begin{array}{l}\text { 4- Open inquiry. Students investigate questions that are student formulated } \\
\text { through student designed/selected procedures }\end{array}$ & & & \\
\hline
\end{tabular}

Gómez, 2015). It is necessary to break apart the lump of inquiry teaching into concrete and measurable processes or practices.

Researchers have designed rubrics or observation protocols for the assessment of inquiry teaching (Bodzin \& Beerer, 2003; Greer, Hudson, \& Wiersma, 1999; Marshall, Smart, \& Horton, 2009; Sawada, 2002). Many of the rubrics contain rich content targeting not only the properties of inquiry teaching but also that of other formats of teaching. Those rubrics contribute to a comprehensive understanding of good teaching in general in educational research but may overwhelm novice science teachers with the complexity and distract them from grasping the core of inquiry teaching. Besides, many rubrics involve subjective grading in terms of the interpretation of the intention underlying teaching practices from observers' perspective. Thus, there is a need of a concise and teacher-friendly rubric that can provide guideline of concrete practices of inquiry teaching. This is especially critical in science teacher education because pre-service teachers (PST) are important agent to transforming science teaching. Without such an instrument, the emphasis of educational theories about inquiry teaching in science teacher education cannot successfully transfer to PSTs' competence of implementing inquiry teaching in science classes. PSTs would claim to embrace inquiry teaching but fail to carry it out authentically (Capps \& Crawford, 2013). It is also difficult to reflect on the effectiveness of formal teacher training on inquiry teaching and monitor PSTs' practice in the field (Wang \& Sneed, 2019). In this study, we designed a rubric to assess PSTs' practical knowledge of one specific type of inquiry teaching, i.e. the 3E cycle derived from the 5E model (Bybee, 1997). The items from the 3E rubric were practices translated from the 5E theory. Our research questions are:

Q1. Is the 3E rubric reliable to assess PSTs' practical knowledge of inquiry teaching?

Q2. Is the 3E rubric valid to assess PSTs' practical knowledge of inquiry teaching?

\section{THEORETICAL FRAMEWORK}

\section{Inquiry Teaching}

Inquiry teaching is one specific pedagogical approach that aligns with the constructivist epistemology that knowledge is generated through making sense of exploratory experiences (Crawford, 2014). Unlike scientific inquiry and inquiry learning, inquiry teaching has a focus on the instructional decisions or actions made by teachers (Osborne, 2014). Although there is no universal definition, inquiry teaching has two emblematic characteristics (Minner, Levy, \& Century, 2010; Minstrell, 2000; Wang, 2019; Windschitl, 2003). First, science is presented as systematically inducted findings rather than fragmentally imparted facts. Pedagogically, this is achieved by presenting science in a sequence of activities in line with scientific inquiry, such as conducting exploration, collecting data, and drawing conclusion. Secondly, teaching happens in a student-centered environment where teachers monitor and facilitate students' learning progress. Pedagogically, students are motivated by an engaging activity, a solvable challenge, or a real-life problem, which makes learning relevant to them, or they are held accountable for their learning by actively participating in various classroom activities. The two characteristics apply to all inquiry teaching along its spectrum from confirmation inquiry to open inquiry (Banchi \& Bell, 2008). The difference lies in the extent to which teachers involve in the three instructional activities of questioning, investigation, and explanation (Table 1). 
Inquiry teaching is also being abused due to its loose definition. Crawford (2014) discusses five myths about inquiry teaching:

Myth 1: All science subject matter should be taught through inquiry.

Myth 2: True inquiry occurs only when students generate and pursue their own questions. Myth 3: Inquiry teaching occurs easily through use of hands-on or kit-based instructional materials.

Myth 4: Student engagement in hands-on activities guarantees that inquiry teaching and learning are occurring.

Myth 5: Inquiry can be taught without attention to subject matter. (p. 516)

Those myths correspond to the inaccurately over-simplified definition of inquiry teaching criticized by Kirschner et al. (2006), which are also common problems PSTs experience when they first implement inquiry teaching. Those myths suggest that inquiry teaching should be framed as one candidate approach to science teaching (Myth 1) epitomized by minds-on rather than hands-on activities (Myths $2-4$ ) in the attempt to deepen students' conceptual understanding (Myth 5). Together, the guidelines above direct our work of designing the $3 \mathrm{E}$ rubric to evaluate PSTs' practical knowledge of inquiry teaching.

\section{The 3E Learning Cycle}

In this study, we derive a 3E rubric from the 5E model (Bybee et al., 2006). As outlined by Liu et al. (2009), this 5E model defines 5 phases of teaching:

Engage: The teacher assesses students' prior knowledge and engages students in learning a new concept. The teacher also helps students make connections between prior and present knowledge and helps to organize students' thoughts about the learning outcomes of present activities.

Explore: The teacher provides students with a common base of activities reflective of present concepts processes, and skills. Students complete activities by using prior knowledge to generate new ideas, to explore questions and possibilities, and to execute a preliminary investigation.

Explain: The teacher focuses students' attention on a specific aspect of their "engagement" and "exploration" experiences and provides opportunities for students to demonstrate their understanding or skills. The teacher can also use direct instruction and guide the students toward a deeper understanding of a concept.

Elaborate: The teacher challenges and extends students' conceptual understanding and skills. Students learn to develop broader and deeper understanding and skills, through the above three phases.

Evaluate: The teacher evaluates students' progress toward achieving the instructional goals. Students learn to assess their understanding and abilities. (p. 345)

The 5E model specifies an operational structure of inquiry teaching that matches the characteristics stated above. The phases of Engage and Explore function to stimulate students' interest or curiosity and grant them direct access to scientific phenomena for exploration, which align with the student-centered characteristic of inquiry teaching. The phase of Explain addresses the reflection of students' experience of exploration and the summary of underlying scientific content knowledge, which steers clear of the "hands-off" inquiry (Crawford, 2014). The sequence from Engage to Explore and to Explain is aligned with the constructivist epistemology that knowledge construction or development happens after students fully experience a scientific phenomenon. The two properties of the 5E model differentiates it from direct instruction which has two salient features of teacher imparting knowledge directly to students without few opportunities for knowledge construction and student-engaged activities like labs serve to verify given knowledge (Wang, 2019). The phase of Elaborate is for students to apply newly obtained knowledge in a different context. Evaluate, both formative and summative, could be a separate phase or a component embedded in other four Es. Elaborate and Evaluate also contribute to knowledge construction, but they lean more toward knowledge assessment.

The 5E model is an advantageous framework for elementary PSTs to develop preliminary understanding of not only what inquiry teaching is but also how it should be implemented in instructional practice. There is evidence supporting that the 5E model successfully promotes students' conceptual understanding (Liu et al., 2009; Wilder \& Shuttleworth, 2005). The 5E model has also been used as a template for lesson plan and delivery in teacher preparation programs. Yet, there is not a rubric assessing PSTs' practical knowledge of the 5E model. In addition, it is claimed that the five E phases cross multiple lesson periods to avoid rushing through each phase (Bybee et al., 2006). This condition is practically challenging in science teacher education because PSTs, as novice teachers, are normally incapable to design a series of internally-consistent lessons or endowed limited access to students in their field practicum to teach several lessons in a row (Wang, 2019). Considering this situation, we extract Engage, Explore, and Explain from the 5E model to design the rubric. Besides the practical reason, this decision also results from the fact that the three phases constitute a complete cycle of inquiry that includes all three key activities (Table 1) of raising question (Engage), conducting exploration (Explore), and drawing conclusion (Explain). As illustrated before, the three phases also represent the key features of inquiry teaching, which could promote students' 
accountability in science learning and epistemic knowledge about scientific inquiry (Windschitl, 2003). Thus, we believe that the 3E rubric is sufficient to facilitate PSTs with their early experience with inquiry teaching.

\section{LITERATURE REVIEW}

To our knowledge, instruments assessing inquiry teaching were primarily designed in the decades of 1990s2000s. Sampson (2004) designed the Science Management Observation Protocol (SMOP) tool that assessed inquiry teaching, but through examining classroom management. SMOP consisted of 25 observable classroom characteristics and teacher actions called descriptions. Observers were expected to score the characteristics and actions on a $0-4$ scale with 0 representing never observed and 4 meaning it was present or very descriptive. While many of the classroom characteristics and teacher actions were connected to inquiry teaching, the link was primarily focused on classroom management. Most descriptions addressed safety, material storage, lesson transition, and classroom routines that apply to other formats of good teaching. For example, one description was to observe if "The teacher assigns clean-up duties to specific individuals" (Sampson, 2004, p. 32). Another description observed if "Students [knew] where to find safety equipment and what to do if there is a fire or accident" (Sampson, 2004, p. 33). Undoubtedly, classroom management is critical to inquiry teaching, but not directly related to the core characteristics of inquiry teaching. Thus, SMOP was limited in assessing a teacher's ability to implement inquiry teaching.

Sawada et al. (2002) designed the Reformed Teaching Observation Protocol (RTOP) to define and measure reformed science/math instruction in terms of being inquiry-oriented and student-centered. RTOP has 25 items associated with 3 factors: lesson design and implementation, content, and classroom culture. The validity and reliability of RTOP items were justified. Like SMOP, many of the items in this instrument pertain not only to inquiry teaching but also other formats of teaching. For instance, the items of respecting students' prior knowledge (Item 1- lesson design and implementation), promoting strongly coherent conceptual understanding (Item 7 - content), and being patient with students (Item 23 - classroom culture) could apply to direct instruction as well. As for the items pertaining exclusively to inquiry teaching, the description was general that lacks practical guidance. Take Item 24 for example, i.e. "The teacher acted as a resource person, working to support and enhance student investigations", it is unclear what observable acts from a teacher could indicate that he/she acts as a resource person. It is undefined what counts as supporting students. Without specification, this item could convey to novice teachers a "hands-off" view of inquiry teaching where they just need to provide materials to students and walk around without telling students the answer during investigation. Alternatively, it could also convey to novice teachers that they should give students whatever support they need during investigation, including directly giving students the lab procedure or result that they are supposed to create by themselves.

Greer, Hudson, and Wiersma (1999) identified the need to accurately assess constructivist teaching, which is equivalent to inquiry teaching according to their definition. Thus, Greer, Hudson, and Wiersma (1999) developed a Constructivist Teaching Inventory (CTI) based on the constructivist theory to assess a teacher's teaching practice in the classroom. The CTI consisted of four scales: teaching strategies scale, community of learner scale, learning activities scale, and curriculum-assessment scale. Each scale contained 11 observable items that were scored on a 7point Likert scale (0-6). Overall, the instrument was considered reliable and valid when measuring constructivist teaching. However, the CTI relied heavily on student outcome and required close analysis of the student-teacher discourse that occurs in the classroom. Furthermore, CTI was created to be very general and did not focus specifically on science teaching. For example, in the teaching strategies scale observers were asked to score the teacher based on an undefined role of inquiry, "Teacher's primary role is to facilitate critical student inquiry, not to provide knowledge, skills, and answers" (Greer, Hudson, \& Wiersma, 1999, p. 27). Another example would include, "Teacher routinely has consistent awareness of students' understanding" (Greer, Hudson, \& Wiersma, 1999, p. 28). While these aspects of inquiry are consistent with constructivist theories, it is subjective to assess the teacher's awareness.

Marshall, Smart and Horton (2009) developed EQUIP, Electronic Quality of Inquiry Protocol, as an instrument to assess quantity and quality of inquiry teaching implementation. EQUIP was designed to focus primarily on inquiry-based instructional practice in both the science and math classroom. The face and construct validity of this instrument have been justified. The motivation behind EQUIP was to inform teachers about their instructional practice across multiple content areas and examine the effectiveness of professional development programs. EQUIP had a total of nineteen indicators categorized into four constructs of inquiry teaching: instruction, curriculum, discourse and assessment. The indicators were scored on a 4-point scale that ranged from level 1 (pre-inquiry) to level 4 (exemplary inquiry). The indicators of instruction measured teachers' instructional delivery (i.e. degree of lecture), order of activities (i.e. the sequence of exploration and instruction), a teacher's role (i.e. center of lesson or facilitator), students' role (passive or active learners), and knowledge acquisition (mastery of facts or developing deep understanding). EQUIP addressed inquiry teaching comprehensively, but at a subjective level. For instance, the frequency of teacher lecturing or being a facilitator was not clearly defined, neither was the extent to which 
student learning being focused on conceptual understanding. In addition, different instructional activities were not distinguished but grouped together as a single entity. Thus, the assessment of an inquiry lesson was based on an observer's general impression more than specific events. Moreover, a few indicators required a heavy load of information analysis (e.g. discourse analysis in class), which is unwieldy to assess the teaching from a massive number of teachers.

In a similar sense, Bodzin and Beerer (2003) developed an instrument STIR, The Science Teacher Inquiry Rubric. The rubric STIR defined learner-centered versus teacher-centered instruction from two perspectives: teacher behavior and learner behavior. Assessing the teacher behavior concentrated on whether the teacher engaged students with questions, promoted student-oriented investigation to gather evidence, and encouraged the use of evidence when drawing conclusions. Correspondingly, assessing the student behavior concentrated on whether students formulated conclusions from evidence, evaluated conclusions in light of alternative ones, and communicated and justified their proposed conclusions. STIR was initially created for elementary school teachers as a self-assessment tool on their specific practices of inquiry teaching. This rubric is convenient to use because it served as a checklist of instructional practices. Despite the high reliability indicated by the correlation between the grading from observers and teachers, the assessment based on STIR was not quantified. There was no summary of the criteria in terms of a level or a score. Thus, it is difficult to bring the variable of inquiry teaching indicated by STIR into statistical analyses for model building or instrument validation. In addition, teacher behavior of inquiry teaching was oversimplified into three practices of engaging students in raising questions, planning investigation, and drawing conclusions. Each practice needed to be further decomposed into components that can represent the quality of that practice.

As illustrated above, the existing instruments measuring inquiry teaching had limitations in terms of being peripheral (Sampson, 2004; Sawada et al., 2002), general/subjective (Bodzin \& Beerer, 2003; Greer, Hudson, \& Wiersma, 1999; Marshall, Smart \& Horton, 2009; Sawada et al., 2002), unwieldy (Greer, Hudson, \& Wiersma, 1999; Marshall, Smart and Horton, 2009), or unquantified (Bodzin \& Beerer, 2003). In this study, we addressed those limitations by designing a $3 \mathrm{E}$ rubric based on one specific type of inquiry teaching, the 5E model. To reduce subjectivity in grading, we borrowed the idea from Bodzin and Beerer (2003) that the assessment targeted what a teacher does (e.g. providing opportunity for students to share their exploration experience) rather than an observer's general impression of how well a teacher does (e.g. a teacher occasionally or often raising questions). Furthermore, the 3E rubric assesses teachers' instructional practices but not learners' behaviors because learners' behaviors in a class are affected by many uncontrollable factors, like their background, personality or even their mood on a specific day. The expectation on learner behavior would be especially challenging to PSTs who have limited teaching experience and access to students in their field practicum. The 3E rubric in this study has a 10point scale for research purposes. It is also a guideline for PSTs to design and review their teaching. Observers would assess a PST's inquiry teaching partially based on evidence identified by that PST as a representation of his/her understanding of the $3 \mathrm{E}$ cycle. In the following sections, we will introduce our $3 \mathrm{E}$ rubric and test its validity and reliability.

\section{METHODS}

\section{Participants and Context}

This study took place in a science methods course for elementary PSTs offered by a large Southern university in the United States. There were 76 female elementary PSTs participating in this study. The ethnicity composition was 60 Whites (79.0\%), 14 Hispanics (18.4\%), and 2 Asians (2.6\%). The PSTs were in the second block of a fourblock ( 2 years in total) program. They visited the field either one full day or two half days a week to observe and learn from their mentor teacher. They had only one opportunity to teach a full science lesson (15-30 minutes) throughout the entire semester. Many of them could only accomplish the first three Es within that limited amount of time. This is why we designed a rubric to assess three Es rather than all five Es. This was the only science methods course in the teacher preparation program for the PSTs. They met in different sections of this methods course once per week for 3 hours. In this course, the PSTs learned the 5E model and other pedagogical strategies. They also observed their instructor modeling science lessons through the 3E cycle. Tasks required on the PSTs included quizzes that assessed the PSTs' declarative knowledge (i.e. knowledge demonstrated from PSTs' answer to test questions describing an artificial teaching scenario) as well as a teaching assignment that assessed the PSTs' practical knowledge (i.e. knowledge demonstrated by PSTs' acts during their teaching in an authentic setting) of the $3 \mathrm{E}$ cycle. The instructors communicated with the PSTs about why they had to use the 3E cycle in the teaching assignment as that the PSTs needed more practice with inquiry teaching due to their limited accesses to it in their own science learning and/or field practicum rather than that inquiry teaching is the optimum approach to science instruction. This was how we addressed "Myth 1: All science subject matter should be taught through inquiry." 
Table 2. The 10 points rubric assessing PSTs' practical knowledge of the $3 E$ cycle Definitions

Engage: The phase where the teacher assesses students' prior knowledge and engages students in learning a new concept. The teacher also helps students make connections between prior and present knowledge, and helps to organize students' thoughts about the learning outcomes of present activities.

Explore: A phase where the teacher provides students with a common base of activities reflective of present concepts, processes, and skills. Students complete activities by using prior knowledge to generate new ideas, to explore questions and possibilities, and execute a preliminary investigation.

Explain: A phase where the teacher focuses students' attention on a specific aspect of their "engagement" and "exploration" experiences and provides opportunities for students to demonstrate their understanding or skills. The teacher can also use direct instruction and guide the students toward a deeper understanding of a concept.

\begin{tabular}{|c|c|c|}
\hline Code & $1 \mathrm{pt}$ & 0 pt \\
\hline Engage $A$ & $\begin{array}{l}\text { The identified phase of Engage is aligned with the definition, } \\
\text { and connected to the lesson objective. }\end{array}$ & $\begin{array}{l}\text { The identified phase of Engage is not aligned with the } \\
\text { definition or not related to the lesson objective. }\end{array}$ \\
\hline Engage $B$ & $\begin{array}{l}\text { The PST is redirecting, prompting or challenging students or } \\
\text { soliciting ideas from students. }\end{array}$ & $\begin{array}{l}\text { The PST is verifying, correcting or completely ignoring } \\
\text { student answers, or explicitly defining the target concept. }\end{array}$ \\
\hline Engage $\mathrm{C}$ & $\begin{array}{l}\text { The PST conducts activities that are likely to mentally involve } \\
\text { students in the thinking of the objective, such as connecting } \\
\text { the objective to related science topics, presenting real-life } \\
\text { examples or posing a thought-provoking task related to the } \\
\text { objective. }\end{array}$ & $\begin{array}{l}\text { The PST conducts activities that are unlikely to mentally } \\
\text { involve students in the thinking of the objective, such as } \\
\text { enacting a fun activity without stimulating students' thinking } \\
\text { or simply reviewing prior knowledge without tying it to the } \\
\text { objective. }\end{array}$ \\
\hline Explore A & $\begin{array}{l}\text { The identified phase of Explore is aligned with the definition } \\
\text { and related to the lesson objective. }\end{array}$ & $\begin{array}{l}\text { The identified phase of Explore is not aligned with the } \\
\text { definition or not related to the lesson objective. }\end{array}$ \\
\hline Explore B & $\begin{array}{l}\text { The PST gives enough instruction on the method of Explore } \\
\text { and the students' actions are aligned with the instruction. }\end{array}$ & $\begin{array}{l}\text { The PST gives insufficient instruction on the method of } \\
\text { Explore so that the students' actions are not aligned with the } \\
\text { instruction. }\end{array}$ \\
\hline Explore C & $\begin{array}{l}\text { The PST clearly communicates the purpose of Explore with } \\
\text { students and the Explore activity has the potential to achieve } \\
\text { the objective. }\end{array}$ & $\begin{array}{l}\text { The PST does not clearly communicate the purpose of } \\
\text { Explore with students or the Explore activity is unlikely to } \\
\text { achieve the objective. }\end{array}$ \\
\hline Explain A & $\begin{array}{l}\text { The identified phase of Explain is aligned with the definition } \\
\text { and related to the lesson objective. }\end{array}$ & $\begin{array}{l}\text { The identified phase of Explain is not aligned with the } \\
\text { definition or not related to the lesson objective. }\end{array}$ \\
\hline Explain B & $\begin{array}{l}\text { The PST clearly and accurately summarizes or guides } \\
\text { students to summarize the key knowledge related to the } \\
\text { lesson objective. }\end{array}$ & $\begin{array}{l}\text { The PST does not clearly or accurately summarize or guide } \\
\text { students to summarize the key knowledge related to the } \\
\text { lesson objective. }\end{array}$ \\
\hline Explain C & $\begin{array}{l}\text { The PST provides opportunities for students to refer to their } \\
\text { experiences or findings from Explore in the class discussion } \\
\text { or their explanation, which contributes to their } \\
\text { understanding of the objective. }\end{array}$ & $\begin{array}{l}\text { The PST provides few opportunities for students to refer to } \\
\text { their experiences or findings from Explore in the class } \\
\text { discussion or their explanation, or their experience shared } \\
\text { contributes little to their understanding of the objective. }\end{array}$ \\
\hline Connection & $\begin{array}{l}\text { The phases of Engage, Explore, and Explain are logically } \\
\text { consistent and closely related to the lesson objective }\end{array}$ & $\begin{array}{l}\text { The phases of Engage, Explore, and Explain are not logically } \\
\text { consistent or not closely related to the lesson objective }\end{array}$ \\
\hline
\end{tabular}

\section{The 3E Rubric}

We designed a 10-point rubric to assess the PSTs' knowledge of Engage, Explore, and Explain in their teaching. This rubric is built upon the definitions of the three Es (Bybee et al., 2006; Liu et al., 2009). It decomposes each E into three binary criteria based on a specific function or characteristic of that E (Table 2). Moreover, an additional criterion was added about the connection between the three Es to ensure the lesson flows naturally and logically from one phase to another. We also considered the myths of inquiry teaching (Crawford, 2014) while designing this rubric. For example, we addressed "Myth 2: True inquiry occurs only when students generate and pursue their own questions" with Explore B stating that PSTs should give sufficient instruction on the method of exploration. We addressed "Myth 4: Student engagement in hands-on activities guarantees that inquiry teaching and learning are occurring" with Engage $C$ addressing the importance of mental engagement. We addressed "Myth 5: Inquiry can be taught without attention to subject matter" with Explain B stating that PSTs should clearly and accurately summarize or guide students to summarize the target content knowledge. Generally, the 10-point scale assesses PSTs' practical knowledge of the $3 \mathrm{E}$ cycle in their teaching. The more points a PST earns, the more knowledgeable the PST is about the $3 \mathrm{E}$ cycle.

There were two rules associated with the use of this rubric. First, each PST needed to report their lesson objective and distinguish the periods of time, start and end, for each of the three Es that occurred in their lesson while submitting their teaching video. The 3E rubric was applied based on the evidence from video segments designated by PSTs instead of the grader's perception of the video. PSTs had an opportunity to self-reflect on their teaching when they identified and labeled the three Es in their video. This design was an additional measurement of PSTs' knowledge of the 3Es and a strategy to increase the inter-rater reliability. Secondly, this rubric was for the 
assessment of PSTs' practical knowledge of expanding a science lesson through the 3E cycle. The focus was on a PST's pedagogical practices rather than the actual quality or effectiveness of a phase, which was also determined by the uncontrollable variable of students. Take Engage for instance, students could be negatively influenced by a variety of factors like bad weather or unfriendly peers that impeded their engagement in a topic regardless of how well a PST strived to engage them. In that case, the 3E rubric would credit that PST's practice over the effectiveness of Engage.

The following scenario is an example of the application of the 3E rubric. A PST taught a lesson to 5 third-grade students with the objective that "Students will be able to explain the importance of using a thermometer to measure temperature when observing and describing weather". She identified the three Es in her lesson as Engage: 00'00" - 02'44", Explore: 02'44" - 05'58", and Explain: 05'58" - 14'40". During Engage, she showed her students a picture of a sunny day with a blue sky, the sun, green grass, and a green tree. She asked the students to describe the weather in this picture. After the students gave the answers of "sunny", "warm", "hot" etc. She showed the students another picture of a sunny day with a blue sky, the sun, and trees and ground covered with snow. She also asked the students to describe the weather in the picture. This time, the students gave the words of "cold", "sunny", "chilly" etc. After soliciting students' reasoning, the PST raised the questions of "how do you know it is cold when the sun is out as well (2nd picture)?", "Is it possible for it to be cold when the sun is out (1 ${ }^{\text {st }}$ picture)?", "Is it possible for two people to be standing in the same place and feeling something different?" Then the PST shifted to Explore by having the students feel ice or warm water before touching room-temperature water, and describe their feelings on an index card. Afterwards, she started the phase of Explain by first sharing the students' answers on the index cards. Then she had the students discuss why there were different answers from those who felt the same water. Through the discussion, she led the students to conclude that a thermometer is needed to solve the disagreement on feelings. Finally, she verbally summarized what temperature is, what a thermometer is, and how they are used to describe weather.

This lesson received 1 point for Engage A (Table 2) because the PST was using two pictures to explicate the students' ways of describing weather and prompted them to reflect on the accuracy of those ways with a dilemma that "two pictures represented different types of weather even though they both had the sun out." It received 1 point for Engage B and 1 for Engage C because the PST did not teach the students the key concepts of thermometer and temperature but immersed them in a problem involving those concepts. This problem had the potential to mentally engage students to think about the accuracy of weather descriptions with the terms of "warm" or "cold". This lesson received 1 point for Explore $A$ as the activity of feeling the same water but reaching different conclusions did further expose students to the problem of inaccurate temperature measurement and necessitate an approach of scientific measurement. The PST gave clear instruction on how the students should feel the water, but she did not communicate with them why they needed to do that. Thus, this lesson received 1 for Explore B but 0 for Explore C. During Explain, the PST summarized the lesson objective. The necessity of a thermometer and temperature was well supported by the activities in Engage and Explain. The PST valued the students' exploration by discussing their index cards, and she summarized the target knowledge to make sure that the students took away the correct information. Thus, this lesson received 1 for Explain A, B, and C respectively. The logic of the three phases was clear and reasonable (Connection: 1 point). Overall, this lesson received 9/10 based on our rubric. This score, 90\%, indicates that this PST had sufficient practical knowledge to design a well-structured lesson involving Engage, Explore, and Explain. Theoretically, this lesson had a greater potential to engage students in productive knowledge construction about the topic of temperature and thermometer.

\section{Data Collection and Analysis}

RQ1, reliability. The data source for this question is the teaching assignment. The PSTs were required to individually design a complete $3 \mathrm{E}$ science lesson and implement it in clinical settings toward the end of the semester. Before they taught, they discussed their lesson plan with the instructor on an individual basis. They were encouraged to teach their lesson to an entire class of elementary students in a formal classroom setting if it could be approved and arranged by their mentor teacher. Otherwise, they could teach their lesson to a group of students ranging from 4 to 8 . Their lesson was between $15-30$ minutes long. The requirements of this assignment resulted from a balanced consideration between the fact that the PSTs were still at the early stage of teacher training and that they only had one opportunity to teach a science lesson while taking the methods course. Among those PSTs, $58(76.3 \%)$ taught their lesson to a group of students and $18(23.7 \%)$ taught it to a class. Each PST had a filming tool kit for their teaching, which included a carry-on microphone and a rotatable video camera that followed the microphone. Thus, a PST's words and acts could be clearly recorded. It is necessary to point out that most of the PSTs' lesson objectives were determined by their mentor teacher, which in most cases had already been taught. Thus, the PSTs were strengthening students' understanding rather than teaching a new concept with their $3 \mathrm{E}$ lesson. 
Table 3. Interrater reliability coefficients

\begin{tabular}{|c|c|c|c|c|}
\hline \multicolumn{5}{|c|}{ Individual binary items } \\
\hline Code & $\mathbf{n}$ & Raters & Fleiss's kappa & p-value \\
\hline Engage $\mathrm{A}$ & 76 & 3 & 0.331 & 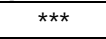 \\
\hline Engage $\mathrm{B}$ & 76 & 3 & 0.572 & *** \\
\hline Engage $\mathrm{C}$ & 76 & 3 & 0.685 & *** \\
\hline Explore A & 76 & 3 & 0.309 & *** \\
\hline Explore B & 76 & 3 & 0.648 & *** \\
\hline Explore C & 76 & 3 & 0.485 & $* * \star$ \\
\hline Explain A & 76 & 3 & 0.266 & $* \star *$ \\
\hline Explain B & 76 & 3 & 0.422 & *** \\
\hline Explain C & 76 & 3 & 0.731 & *** \\
\hline Connection & 76 & 3 & 0.597 & $* * *$ \\
\hline \multicolumn{5}{|c|}{ Categorical and total scores } \\
\hline Code & $\mathbf{n}$ & Raters & $\operatorname{ICC}(3)$ & p-value \\
\hline Engage & 76 & 3 & 0.833 & $\star \star \star *$ \\
\hline Explore & 76 & 3 & 0.815 & $* * *$ \\
\hline Explain & 76 & 3 & 0.859 & $* * *$ \\
\hline Total & 76 & 3 & 0.869 & 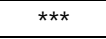 \\
\hline
\end{tabular}

Note: ns, not significant; ${ }^{*}, \mathrm{p}<0.05 ;{ }^{* *}, \mathrm{p}<0.01 ;{ }^{* * *}, \mathrm{p}<0.001$

Each video was scored by the three authors separately. We gave a binary score (i.e. 1 or 0 ) to each item (e.g. Engage A, Explore C, etc.), summed the three items associated with an E phase as the category score (e.g. Engage = Engage A + Engage B + Engage C), and summed all 10 items as the total score. The category score for each E had a maximum of 3 points and the total score had a maximum of 10 points. We recorded evidence from a video to justify our grading, such as what a PST did to engage students and why it was mentally engaging. However, we did not share our evidence or discuss our grading to reach inter-rater agreement. Instead, we analyzed the interrater reliability on the scores given by three of us individually. Specifically, we used Fleiss's kappa (Fleiss, 1971) on each individual item and Intraclass Correlation Coefficient (ICC, Bartko, 1966) on the categorical score of each E and the total 3E score. We adopted the kappa values (Landis \& Koch, 1977) to describe the level of agreement: <0, poor agreement; $0.01-0.20$, slight agreement; $0.21-0.40$, fair agreement; $0.41-0.60$, moderate agreement; 0.61 0.80 , substantial agreement; $0.81-1.00$, excellent agreement. As for ICC, we calculated ICC 3 of three fixed raters with the scale of reliability: $<0.5$, poor reliability; $0.5-0.75$ moderate reliability; $0.75-0.90$, good reliability; $>0.9$, excellent reliability.

RQ2, validity. In the section of theoretical framework, we discussed how we derived the $3 \mathrm{E}$ rubric from the $5 \mathrm{E}$ model (Bybee et al., 2006), which justified its theoretical validity. In addition, we tested the convergent validity of this rubric by examining the correlation between PSTs' declarative and practical knowledge of the 3E cycle. Each PST took a quiz that contained four multiple-choice questions regarding the 3E cycle (Appendix), which had been validated (Wang \& Sneed, 2019). The PSTs' score of those 4 questions (maximum $=4$ points) represented their declarative knowledge of the $3 \mathrm{E}$ cycle. As stated earlier, each of us graded the 3E videos from each PST separately based on the 3E rubric (Table 2). Then we averaged the scores from the three graders as a PST's teaching score, which represented their practical knowledge of the $3 \mathrm{E}$ cycle. The two types of knowledge should be inter-related to a certain level (Cochran-Smith \& Lytle, 1999). Correspondingly, we ran Pearson correlation (Cohen, Manion, \& Morrison, 2007) between the two variables with the scale of $\pm(0-0.3)$, weak positive/negative correlation; $\pm(0.3-$ $0.7)$, moderate positive/negative correlation, and $\pm(0.7-1)$, strong positive/negative correlation. Considering that the context of teaching, i.e. a small group versus a large class, might affect a PST's practical knowledge of the 3E cycle. We ran Pearson correlation on the samples of both all PSTs $(n=76)$ and those PSTs teaching to a small group of students $(n=58)$.

\section{FINDINGS AND DISCUSSIONS}

\section{Q1. Is the 3E Rubric Reliable to Assess PSTs' Practical Knowledge of Inquiry Teaching?}

We summarize the data of Fleiss's kappa and ICC in Table 3. The interrater agreement is substantial on Engage C (0.685), Explore B (0.648), and Explain C (0.731), moderate on Engage B (0.572), Explore C (0.485), Explain B (0.422), and Connection (0.597), fair on Engage A (0.331), Explore A (0.309), and Explain A (0.266). Without any discussion, the three graders' interpretations of the $3 \mathrm{E}$ rubric are relatively consistent (kappa >0.4) on 7 out of 10 items. The disagreement lies in determining whether the three phases identified by a PST are aligned with their definition or connected to the lesson objective, i.e. Engage A (0.331), Explore A (0.309), and Explain A (0.266). This suggests that the three items contain the most subjectivity or vagueness that need to be clarified. The ICC (3) 
coefficients for the categorical and total scores demonstrate good interrater reliability. In other words, the assessments of a PST's skill of using Engage, Explore, and Explain in science teaching are consistent among the three graders. This finding supports the reliability of the $3 \mathrm{E}$ rubric.

\section{Q2. Is the 3E Rubric Valid to Assess PSTs' Practical Knowledge of Inquiry Teaching?}

Considering the high interrater reliability $(\mathrm{ICC}=0.869)$ among the three graders, the average of the three $3 \mathrm{E}$ scores on a video can reliably represent the rating of a PST's practical knowledge of the 3E cycle. In case of all the 76 PSTs, their practical knowledge from videos has a mean of 8.51/10 (10 is the maximum score) and a standard deviation of 1.58. Their declarative knowledge from questions has a mean of 2.33/4 and a standard deviation of 0.79. The Pearson correlation between the two variables is 0.22 (weak). As for the 58 PSTs who taught their lesson to a group of students, their practical knowledge has a mean of 8.79/10 (10 is the maximum score) and a standard deviation of 1.27. Their declarative knowledge has a mean of 2.38/4 and a standard deviation of 0.75 . The Pearson correlation between the two variables is 0.35 (moderate). As suggested by the correlation coefficients, there is a better alignment between the PSTs' declarative and practical knowledge in small-group teaching $(r=0.35)$ than in whole-class teaching $(r=0.22)$. This result is reasonable considering that PSTs need to consider more factors while teaching to a whole class, such as classroom management and student grouping. As novice teachers, they may be distracted by those factors in a way that they fail to implement the $3 \mathrm{E}$ lesson exactly as planned. The moderate correlation in small-group teaching supports the convergent validity of the $3 \mathrm{E}$ rubric.

\section{CONCLUSIONS AND IMPLICATIONS}

This study is our first step to bridge the gap between the theoretical emphasis and operational incompetence of inquiry teaching (Capps \& Crawford, 2013; Marek, Maier \& McCann, 2008; Meltzer \& Otero, 2015; Odom \& Settlage, 1996). We design a quantitative rubric to measure PSTs' practical knowledge of inquiry teaching in terms of their use of the cycle of Engage, Explore, and Explain from the 5E model (Bybee et al., 2006). We test the reliability and validity of the $3 \mathrm{E}$ rubric through applying it in the context of science teacher preparation. Our data support the inter-rater reliability, theoretical validity, and convergent validity of this rubric. The difference in correlation coefficients between the situations of all the PSTs and those teaching to small groups aligns with previous findings that large class or group size is a challenge to the implementation of inquiry teaching (Brown et al., 2006; Cheung, 2008). This result indirectly supports the theoretical validity of the $3 \mathrm{E}$ rubric. Generally, this $3 \mathrm{E}$ rubric is reliable and valid.

The contribution of this study is two-fold. First, this rubric suggests a practical guideline, not checklist, for PSTs to understand and implement inquiry teaching. The $3 \mathrm{E}$ rubric covers critical components of inquiry teaching, such as mental engagement, purposeful exploration, and experience-oriented explanation (Crawford, 2014; Wang, 2019). It describes concrete practices or features rather than vague theories of inquiry teaching, which could serve as reminders for PSTs to plan for inquiry teaching or guidance for PSTs to reflect on their teaching. Secondly, this rubric endows the quantitative measurement of the quality of the $3 \mathrm{E}$ cycle as one type of inquiry teaching. In science teacher education, a reliable and valid practical instrument can help science teacher educators assess the effectiveness of educational interventions regarding inquiry teaching. Research wise, quantifying the quality of inquiry teaching makes it possible to add this variable into model building, such as the relationship between PSTs' practical knowledge of inquiry teaching and their scientific content knowledge or their students' science learning. In this study, we choose to run correlation between PSTs' declarative and practical knowledge of the 3E cycle. This choice results from our struggle about what variables are determinant or significantly influential to PSTs' practical knowledge, because there has been few large-scale quantitative studies that suggest any (Fook et al, 2016; ZafraGómez, 2015). Correspondingly, the 3E rubric, after being further refined, can fill the gap.

While designing the $3 \mathrm{E}$ rubric, we try to reduce the subjectivity in assessment by focusing on specific instructional practices of PSTs rather than an observer's general impression of the quality of instruction. Grading based on PST-identified evidence also controls the bias of observers' perspective or knowledge of the 3E cycle. In this study, each of us recorded evidence supporting our grading but did not share it in order to analyze the interrater reliability. It is reasonable to assume that sharing evidence along with grading would increase the objectivity of the $3 \mathrm{E}$ rubric even more. On the other hand, the fair interrater reliability in Engage A, Explain A, and Explain A (Table 2) suggests that there is still a certain level of subjectivity and inconsistency in determining the alignment of PSTs' practical knowledge of each phase with its definition. Thus, the definitions of the three E phases need to be further decomposed into concrete practices. 


\section{LIMITATIONS}

The 3E rubric was designed in a specific context of science teacher education in the US where PSTs only had 1530 minutes to teach one science lesson in their clinical teaching. This situation is representative to some extent because PSTs in the US normally do not have autonomy during their field placement. They seldom have chances to design a series of science lessons or have enough time to implement a complete teaching/learning cycle like the $5 \mathrm{E}$ model. This is the reason why we designed the rubric based the first three Es. We are not denying the significance of Elaborate and Evaluate. We are also aware that Elaborate and Evaluate are required in clinical teaching in other contexts of science teacher education. Thus, this $3 \mathrm{E}$ rubric is only a starting point of assessing and guiding PSTs' inquiry teaching. Future work is needed to extend the rubric to all five Es.

Currently, there are three items in each of the first three Es, which are not enough to address all aspects of those E phases. Take Engage for example, one function of Engage is for PSTs to connect students' prior knowledge to the lesson objective. The Engage items provide limited information about PSTs' assessment of students' prior knowledge. This limitation results from the fact that this rubric is aimed to assess observable acts of PSTs rather than their intention behind. A PST can assess students' prior knowledge with a question. However, it is unclear from an observer's perspective whether the PST asks that question intentionally to assess students' prior knowledge or to what extent the PST uses that information to proceed with his/her lesson. Thus, it is challenging to objectively measure PSTs' acts of assessing students' prior knowledge. We will continue to expand each E into more items by translating the properties of that E phase into more measurable acts.

\section{REFERENCES}

Anderson, R. D. (2002). Reforming science teaching? What research says about inquiry. Journal of Science Teacher Education, 13(1), 1-12. https:/ / doi.org/10.1023/A:1015171124982

Bartko, J. J. (1966). The intraclass correlation coefficient as a measure of reliability. Psychological reports, 19(1), 3-11. https:/ / doi.org/10.2466/pr0.1966.19.1.3

Bell, R.L., Smetana, L., \& Binns, I. (2005). Simplifying inquiry instruction. The Science Teacher, 72(7), 30-33.

Bodzin, A. \& Beerer, K. (2003). Promoting inquiry base science instruction: The validation of the science teacher inquiry (STIR). Journal of Elementary Science Education, 15(2), 39-49. https:/ / doi.org/10.1007/BF03173842

Brown, P. L., Abell, S. K., Demir, A., \& Schmidt, F. J. (2006). College science teachers' views of classroom inquiry. Science education, 90(5), 784-802. https:/ / doi.org/10.1002/sce.20151

Bybee, R. W. (1997). Achieving scientific literacy: From purposes to practices. Portsmouth, NH: Heinemann.

Bybee, R. W. (2000) Teaching science as inquiry. In J. Minstrell \& E. van Zee (Eds.), Inquiring into inquiry learning and teaching in science (pp.20-46). Washington, DC: American Association for the Advancement of Science.

Bybee, R. W., Taylor, J. A., Gardner, A., Van Scotter, P., Powell, J. C., Westbrook, A., \& Landes, N. (2006). The BSCS $5 \mathrm{E}$ instructional model: Origins, effectiveness, and applications. Unpublished white paper. Colorado Springs, CO: BSCS.

Capps, D. K., \& Crawford, B. A. (2013). Inquiry-based instruction and teaching about nature of science: Are they happening? Journal of Science Teacher Education, 24(3), 497-526. https:/ / doi.org/10.1007/s10972-012-9314-z

Cheung, D. (2008). Facilitating chemistry teachers to implement inquiry-based laboratory work. International Journal of Science and Mathematics Education, 6(1), 107-130. https:/ / doi.org/10.1007/s10763-007-9102-y

Cochran-Smith, M., \& Lytle, S. L. (1999). Chapter 8: Relationships of knowledge and practice: Teacher learning in communities. Review of research in education, 24(1), 249-305. https:/ / doi.org/10.3102/0091732X024001249

Cohen, L., Manion, L., \& Morrison, K. (2007). Research Methods in Education (6th edition). London and New York: Routledge. https:/ / doi.org/10.4324/9780203029053

Crawford, B. A. (2014). From inquiry to scientific practices in the science classroom. In N. G. Lederman \& S. K. Abell (Eds.), Handbook of Research on Science Education (Vol. 2, pp. 515-541). New York: Routledge.

Fleiss, J. L. (1971). Measuring nominal scale agreement among many raters. Psychological bulletin, 76(5), 378. https:/ / doi.org/10.1037/h0031619

Fook, C. Y., Dalim, S. F., Narasuman, S., Sidhu, G. K., \& Fong, L. L. (2016). Students' Perception of Inquiry-Based Instruction, Active Learning and Formative Assessment in Higher Education. Advanced Science Letters, 22(12), 4422-4425. https:/ / doi.org/10.1166/asl.2016.8173

Freeman, S., Eddy, S. L., McDonough, M., Smith, M. K., Okoroafor, N., Jordt, H., \& Wenderoth, M. P. (2014). Active learning increases student performance in science, engineering, and mathematics. Proceedings of the National Academy of Sciences, 111(23), 8410-8415. https:/ / doi.org/10.1073/pnas.1319030111 
Goldston, M. J., Day, J. B., Sundberg, C., \& Dantzler, J. (2010). Psychometric analysis of a 5E learning cycle lesson plan assessment instrument. International Journal of Science and Mathematics Education, 8(4), 633-648. https:/ / doi.org/10.1007/s10763-009-9178-7

Greer, M. A., Hudson, L. M., \& Wiersma, W. (April, 1999). The constructivist teaching inventory: A new instrument for assessing constructivist teaching practices in the elementary grades. Paper presented at annual meeting of the American Educational Research Association. Montreal: CA.

Hmelo-Silver, C. E., Duncan, R. G., \& Chinn, C. A. (2007). Scaffolding and achievement in problem-based and inquiry learning: a response to Kirschner, Sweller, and. Educational psychologist, 42(2), 99-107. https:/ / doi.org/10.1080/00461520701263368

Kirschner, P. A., Sweller, J., \& Clark, R. E. (2006). Why minimal guidance during instruction does not work: An analysis of the failure of constructivist, discovery, problem-based, experiential, and inquiry-based teaching. Educational psychologist, 41(2), 75-86. https:/ / doi.org/10.1207/s15326985ep4102_1

Kolodner, J. L., Camp, P. J., Crismond, D., Fasse, B., Gray, J., Holbrook, J., Puntambekar, S, \& Ryan, M. (2003). Problem-based learning meets case-based reasoning in the middle-school science classroom: Putting learning by design (tm) into practice. The journal of the learning sciences, 12(4), 495-547. https://doi.org/10.1207/S15327809JLS1204_2

Landis, J. R., \& Koch, G. G. (1977). The measurement of observer agreement for categorical data. biometrics, 159-174. https://doi.org/10.2307/2529310

Liu, T. C., Peng, H., Wu, W. H., \& Ming-Sheng, L. (2009). The effects of mobile natural-science learning based on the 5E learning cycle: A case study. Journal of Educational Technology \& Society, 12(4), 344.

Marek, E. A., Maier, S. J., \& McCann, F. (2008). Assessing understanding of the learning cycle: The ULC. Journal of Science Teacher Education, 19(4), 375-389. https:/ / doi.org/10.1007/s10972-008-9100-0

Marshall, J. C., Smart, J., \& Horton, R. M. (2009). The design and validation of EQUIP: An instrument to assess inquiry-based instruction. International Journal of Science and Mathematics Education, 8, $299-321$. https:/ / doi.org/10.1007/s10763-009-9174-y

Meltzer, D. E., \& Otero, V. K. (2015). A brief history of physics education in the United States. American Journal of Physics, 83(5), 447-458.Minner, D. D., Levy, A. J., \& Century, J. (2010). Inquiry-based science instruction what is it and does it matter? Results from a research synthesis years 1984 to 2002. Journal of Research in Science Teaching, 47(4), 474-496. https:/ / doi.org/10.1119/1.4902397

Minstrell, J. (2000). Implications for teaching and learning inquiry: A summary. In J. Minstrell \& E. van Zee (Eds.), Inquiring into inquiry learning and teaching in science (pp. 471-496). Washington DC: American Association for the Advancement of Science.

National Research Council (NRC). (2012). A Framework for K-12 science education: Practices, crosscutting concepts, and core ideas. Washington, DC: The National Academies Press.

Odom, A., \& Settlage, J. J. (1996). Teachers' understandings of the learning cycle as assessed with a two-tier test. Journal of Science Teacher Education, 7(2), 123-142. https:/ / doi.org/10.1007/BF00114122

Osborne, J. (2014). Scientific Practices and Inquiry in the Science Classroom. In N. G. Lederman \& S. K. Abell (Eds.), Handbook of Research on Science Education (Vol. 2, pp. 579-599). New York: Routledge.

Palmer, D. H. (2009). Student interest generated during an inquiry skills lesson. Journal of Research in Science Teaching, 46(2), 147-165. https:/ / doi.org/10.1002/tea.20263

Sampson, V. (2004). The science management observation protocol. The Science Teacher, 71(10), 30-33.

Sawada, D., Piburn, M. D., Judson, E., Turley, J., Falconer, K., Benford, R., \& Bloom, I. (2002). Measuring reform practices in science and mathematics classrooms: The reformed teaching observation protocol. School science and mathematics, 102(6), 245-253. https:/ / doi.org/10.1111/j.1949-8594.2002.tb17883.x

Wang, J. (2019). Compare scaffolding pedagogical instruction with direct instruction for pre-service science teacher education. International Journal of Science and Mathematics Education. https://doi.org/10.1007/s10763-01910010-7

Wang, J., \& Sneed S. (2019). Exploring the Design of Scaffolding Pedagogical Instruction for Elementary Preservice Teacher Education. Journal of Science Teacher Education. 30(5), 483-506.

Wilder, M., \& Shuttleworth, P. (2005). Cell inquiry: A 5E learning cycle lesson. Science Activities: Classroom Projects and Curriculum Ideas, 41(4), 37-43. https:/ / doi.org/10.3200/SATS.41.4.37-43

Windschitl, M. (2003). Inquiry projects in science teacher education: What can investigative experiences reveal about teacher thinking and eventual classroom practice? Science Teacher Education, 87, 112-143. https://doi.org/10.1002/sce.10044 
Windschitl, M., Thompson, J., \& Braaten, M. (2008). Beyond the scientific method: Model-based inquiry as a new paradigm of preference for school science investigations. Science education, 92(5), 941-967. https:// doi.org/10.1002/sce.20259

Zafra-Gómez, J. L., Román-Martínez, I., \& Gómez-Miranda, M. E. (2015). Measuring the impact of inquiry-based learning on outcomes and student satisfaction. Assessment \& Evaluation in Higher Education, 40(8), 1050-1069. https:/ / doi.org/10.1080/02602938.2014.963836

\section{APPENDIX}

Questions 17 - 20 are based on the scenario described below

One day, a student says: "I know friction. Pushing a heavy object is always harder than a lighter one. So, there is more friction on heavy objects." The teacher plans to design a 5E lesson that guides students to notice that surface smoothness is another factor affecting the magnitude of friction.

Q17. Which of the following is the MOST appropriate way to enact the stage of Engage?

A. The teacher draws a force diagram to explain how friction influences a moving object on the floor

B. The teacher holds a class discussion about what factors can influence the magnitude of friction

C. The teacher prepares a box-pushing competition where two groups of students push two identical boxes on different surfaces, tiles versus a carpet.

D. The teacher has students push three objects of different weights and discuss which one is hardest to push

Q18. Which of the following is the MOST appropriate way to enact the stage of Explore?

A. Students watch a video explaining what factors would influence the magnitude of friction

B. The teacher holds a class discussion about the design of ski blades and ice skates

C. The teacher provides three objects of different weights and a force scale for each group of students. Students conduct a lab to investigate the different readings of the force scale while dragging the three objects on the table

D. The teacher demonstrates a lab of dragging a wood block across three different surfaces between ice, a table, and a rug, records the readings of the force scale, and then has students analyze the readings.

Q19. Which of the following is the MOST appropriate way to enact the stage of Explain?

A. The teacher plays a video explaining how surface smoothness affects the magnitude of friction

B. The teacher collects students' work from the previous stage and dismisses the class

C. The teacher has students share their findings from the previous stage and helps them draw the conclusion about

D. The teacher holds a class discussion about the design of ski blades and ice skates

Q20. Which of the following is the MOST appropriate way to enact the stage of Elaborate?

A. The teacher holds a class discussion about why it is harder for heavy people to slide down slide.

B. The teacher plays a video explaining factors influencing the magnitude of friction

C. The teacher has students work on a question individually for the exit ticket and collects the exit ticket

D. The teacher holds a class discussion about the design of ski blades and ice skates

\section{http://www.ejmste.com}

